\title{
An empirical study on the determinants of essential patent claims in compatibility standards $s^{\text {ts }}$
}

\author{
Rudi Bekkers ${ }^{\mathrm{a}, \mathrm{b}, *}$, René Bongard ${ }^{\mathrm{c}}$, Alessandro Nuvolari ${ }^{\mathrm{d}}$ \\ a Eindhoven Centre for Innovation Studies (ECIS), School of Innovation Sciences, Eindhoven University of Technology, Eindhoven, The Netherlands \\ b Dialogic Innovatie E' Interactie, Utrecht, The Netherlands \\ ' Department of Business Statistics, Statistics Netherlands, Heerlen, The Netherlands \\ d LEM-Laboratory of Economics and Management, Sant'Anna School of Advanced Studies, Pisa, Italy
}

\section{A R T I C L E I N F O}

\section{Article history:}

Received 4 November 2009

Received in revised form 18 April 2011

Accepted 7 May 2011

Available online 11 June 2011

\section{Keywords:}

Essential patents

Compatibility standards

IPR policies

Mobile telecommunications

W-CDMA

Economics of information systems

\begin{abstract}
A B S T R A C T
In the field of compatibility standards, an increasing number of companies claim to own so-called essential patents (i.e. those patents that are indispensable for designing and manufacturing products conforming to the standard). It is widely believed that the ownership of such patents is a very valuable bargaining tool in cross-license negotiations, while for non-producing firms such patents may result in a substantial stream of licensing revenues. In this paper we study the determinants of essential patent claims in compatibility standards. In particular, we assess the role of two main factors: the significance of the technological solution contained in the patent and the involvement of the applicant of the patent in the standardisation process. We examine the case of W-CDMA, one of the most successful standards in mobile telecommunications. We compare the patents claimed essential for this standard with a control group of randomly selected, unclaimed patents covering the same time period and technology classes. We find empirical evidence that both factors have significant impact on the probability that a patent is claimed as essential, but the involvement in the standardisation process is a stronger determinant than the technical value ('merit') of the patent. On the basis of our findings, we offer policy recommendations.
\end{abstract}

(C) 2011 Elsevier B.V. All rights reserved.

\section{Introduction}

Standards have a fascinating and complex relationship with patents. Whereas standards aim at ensuring equal access to the technology for all stakeholders, patents establish temporary, exclusionary rights on the use of inventions. The ensuing tension may be particularly problematic in the case of so-called essential patents, i.e. patents that are indispensible in order to manufacture a product or offer a service based on the standard in question. ${ }^{1}$ To prevent the

\footnotetext{
The views expressed in this paper are those of the author(s) and do not necessarily reflect the policies of Statistics Netherlands.

* Corresponding author at: Eindhoven University of Technology, Room IPO 2.36, P.O. Box 513, 5600BM Eindhoven, The Netherlands. Tel.: +31 40 2475621; fax: +31402474646

E-mail addresses: r.n.a.bekkers@tue.nl (R. Bekkers), r.bongard@hotmail.com (R. Bongard), alessandro.nuvolari@sssup.it (A. Nuvolari).

1 This is reflected in the definition that the European Telecommunications Standards Institute (ETSI) adopted for 'essentiality': '[. . . ] that it is not possible on technical (but not commercial) grounds, taking into account normal technical practice and the state of the art generally available at the time of standardization, to make, sell, lease, otherwise dispose of, repair, use or operate equipment or methods which comply with a standard without infringing that IPR.' (ETSI Rules of Procedure, 26 November 2008, retrieved from http://www.etsi.org).
}

situation in which standards could not be implemented in practice due to the existence of patents covering inventions related with these essential components of the product or service in question, standards bodies have developed policies that establish rules for their members concerning the availability and licensing conditions for essential patents. Most of these policies require the members of the standards body to disclose ('declare') their essential patents. Prima facie, such disclosures may be seen as revealing the technical value of the patent for the standard in question: i.e. the patented technology is chosen to become part of the standard by virtue of its contribution to technical performance, cost-effectiveness, etc. However, the technical content of standards is actually drawn up by members of a standards body, thus offering members that are involved several types of opportunities to influence the very technical content of standards. As a consequence, patents may be brought into the standard (and subsequently declared to be essential) because of strategic reasons. After all, ownership of essential patents brings many advantages, such as licensing revenues, and 'exchange chips' that open the door to attractive cross-licensing arrangements.

This paper examines to what degree patents are claimed to be essential in a standardisation process on the basis of the merit of their specific technological contribution, or the result of the patent 
owner's involvement in the standardisation process (and the strategic opportunities that come along), or both. To do so, we perform an extensive analysis on a publicly available list of self-declared essential patents for W-CDMA, the most successful third-generation standard for mobile telecommunications worldwide. The paper is organised as follows. Section 2 introduces the phenomenon of essential patents and develops two hypotheses concerning their claiming behaviour. Section 3 introduces the empirical data we use to test these hypotheses. In particular, it contains an introduction to the technology in question (i.e. W-CDMA), a discussion of our data set followed by descriptive statistics and some preliminary analyses. Section 4 presents the results of the tests of the hypothesis carried out with a multivariate model. Section 5 concludes the paper and discusses its implications.

\section{Essential patents and compatibility standards}

Standards can evolve in several ways. Sometimes, a particular firm develops a set of technical specifications that becomes so successful that it is regarded as an industry standard. The firm in question might or might not allow other firms to make products or sell services based on its industry standard, by publicising the detailed specifications and/or granting licenses. In case the firm obtains a dominant market position, competition authorities may try to enforce that third parties have better access to the standard (e.g. the decisions of the European Commission on Microsoft Windows). In most cases, however, standards are the result of a negotiation process between two or more (independent) stakeholders (Funk and Methe, 2001). The explicit aim of this process is the creation of a standard that will be widely adopted by stakeholders and/or other parties. We can distinguish between formal standards bodies on the one hand, and consortia and fora on the other. Formal bodies must adhere to a number of criteria, including openness to participate, consensus-based decision-making/due process, open access to documentation, and intellectual property rules (Krechmer, 1998, 2005; Andersen, 2008). Although various different definitions have been proposed in the literature, this paper will refer to formal standards bodies as those that are recognised as such by public authorities (for example, in Europe, Directive 98/34/EC designates CEN, CENELEC, and ETSI to be recognised regional standards bodies). Consortia and fora might also meet these criteria, but may also choose not to do so. Depending on the exact context, firms may prefer one type of standards body (also called standards developing organisations SDOs) over the other; therefore formal standards bodies, consortia and fora (and the many sub-types one can distinguish here) may be seen as competing against each other in the same "market".

Although there were some early cases of tension between patents and standards this was not considered to be a major issue until the late 1980s. By that time, the first major clash had occurred in the telecommunications sector, more specifically when the European Telecommunications Standards Institute (ETSI) developed GSM, a standard for mobile telephony. The clash took place against a background of liberalisation and privatisation in the European telecommunications sector, the so-called pro-patent era (Granstrand, 2005), and the disappearance of exclusive, long-term relations between network operators and their suppliers. This first clash has been extensively documented in the literature (Shurmer and Lea, 1995; Iversen, 1999; Wilkinson, 1991; Bekkers, 2001) and may be considered as the starting point for standard setting bodies to develop specific rules concerning patent ownership.

The most common way in which standard-developing organisations now deal with patents is known as (F)RAND, an acronym that refers to the Fair, Reasonable and Non-discriminatory conditions that parties need to ensure for the licenses of their essential patents.
While the (F)RAND policies in principle cover all types of Intellectual Property Rights (IPR), including copyrights, trademarks, database rights, industrial design rights, patents are virtually the only category of such rights that have been claimed essential to date; hence this paper will use the terms patents and IPRs as interchangeable. The (F)RAND policy was pioneered by ETSI in the early 1990s (and revised and refined several times). Nowadays, virtually all formal SDOs have adopted a (F)RAND policy, as well as many consortia and fora, though there are notable exceptions such as W3C, a body that requires all patents to be royalty-free. In short, (F)RAND's principles are as follows: (1) Holders of IPR, member or not, will be rewarded in a suitable and fair manner; (2) Members will make a reasonable effort to inform the SDO of relevant IPRs of which they are aware. If they propose a technical design to the SDO they will also, in good faith, draw attention to IPRs that could become essential once that proposal is adopted; (3) If an essential IPR is identified, the SDO will request its holder, member or not, to make licenses available under (F)RAND terms; (4) Members can choose not to license an IPR; if they persevere, the SDO will try to change the standard so it no longer draws upon that patent. If it does not succeed, it will withdraw the standard or stop working on it. Note that although this policy does create rights for non-members (e.g. regarding licensing conditions that members can impose), it cannot create obligations for non-members as it does not have any legal relationship with such third parties.

Usually, standards only define the interfaces between elements of a larger system, not the way these elements need to be made. This ensures a maximum incentive to innovate. In this context, it is important to note that the (F)RAND policy refers to 'essential patents'. These are patents that are so basic to the interfaces defined by the standard that it is impossible to design any device that complies with these interfaces without infringing the patent. If there are alternative ways to design something that complies with the standard (even when they are more expensive to implement), the patent in question is no longer essential. Obviously, a particularly critical issue is how the requirement of fair, reasonable and non-discriminatory conditions is to be interpreted. Does the licensing fee need to be reasonable from the perspective of the value of the patent, or reasonable given the total number of other patents that are essential to the standard and the total licensing fee that implementers can afford or want to afford?

\subsection{The technological value of the patent as a determinant of essentiality}

Usually a standard must attain a number of different, often conflicting functional requirements. For example, in the area of telecommunications, a standard for mobile internet data services might aim to (1) offer a high data rate (speed), (2) in a large, continuous coverage area, (3) allowing the user to move with speeds up to $300 \mathrm{~km} / \mathrm{h}$, (4) consuming low power in order to optimise battery life, (5) requiring a minimum number of cell sites or antenna towers, (6) while being robust to noise and other types of interference and (7) at low costs for base stations and terminals. Clearly, certain technological solutions may be able to deal with one or more of these requirements better than others, and given the high propensity to patent prevailing in many "high tech" sectors, it is very likely that many of these attractive technological solutions will be patented. Hence, it is likely that patented technologies may then be chosen to be included in a standard because of their attractiveness. In some cases, a patented technology may be the only feasible way to realise the functional requirements of the standard in question. In other cases, the patented technology may not be the only solution but still be the best way to achieve the standard requirements, by offering a higher performance or making the implementation more cost-effective, etc. In both cases, the patented technology has 
a high degree of merit-or technological value, as one might call it. This leads to our first hypothesis:

Hypothesis 1. The intrinsic technological value of a patent increases the likelihood of that the patent will be claimed essential to a standard.

If we assume that the intrinsic technological value of a patented technological solution for the standard is the sole determinant of its inclusion in the standard (and that strategic considerations, as will be discussed below, do not play any role) then we can expect that essential patents are likely to be of higher value than other patents, all other things being equal. Economists of innovation have attempted to assess the value of patents using a number of characteristics such as citations received, renewals, family size, opposition, etc. (Van Zeebroeck, 2011 provides a detailed survey of this literature). So far, the number of forward citations (i.e., the citations received by a patent) is surely the most popular indicator of patent value. Following the pioneering contributions of Carpenter et al. (1981) and Trajtenberg (1990), various studies have consistently established that forward citations are systematically correlated with the economic value or the industrial importance of patents (see for example, Albert et al., 1991; Sampat and Ziedonis, 2004). The idea behind the use of forward citations as indicator of the value of a patent is relatively straightforward: if a patent receives many citations, this means that the technological solution outlined in the patent serves as a basis for a large number of subsequent technological developments. Another related argument is that if a patent receives many citations, this may also mean that it has been frequently used by patent examiners to reduce the scope of protection claimed by subsequent patents and this again points to the significance of the technological solution contained in the original patent (Van Zeebroeck, 2011). For all these reasons, it seems reasonable to presume that the technological value of a patent will be captured by the number of forward citations. If this is the case, then we can expect that essential patents will typically have a higher number of forward citations than non-essential patents. One might argue that some patents may receive citations as a result of being declared essential. We shall consider explicitly this possibility in more detail in the next section and we conclude that, given the procedures adopted for the construction of our data set, the risk of endogeneity is limited.

Several recent papers have indeed already explored Hypothesis 1 in other contexts. Rysman and Simcoe (2008) conclude that patents declared as essential to standards bodies are cited much more frequently than a set of control patents. Layne-Farrar (2008) goes one step further by looking specifically at patenting taking place after the standard has been set, and concludes that also essential patents in this group are more valuable - i.e. receive more citations - than average patents.

\subsection{Firm strategies and essential patents}

Firms may try to have some of their own patents included in the standards as essential patents for reasons that may go beyond the specific "technological" contribution these patents make to the standard. On reflection, there may be several incentives for this behaviour. Essential patents are not only a potential source of significant revenue but are also valuable 'exchange chips' that open the door to attractive cross-licensing agreements. As demonstrated with the GSM case, ownership of essential patents can be crucial for market entry (Bekkers et al., 2002). Although (F)RAND policies now generally prevent patent owners from systematically blocking others from the market, those market players who do not own any essential patents are usually not in a very enviable position.

To understand better how firms can employ strategies in order to get essential patents, it is useful to look in more detail at the typical standardisation process at formal standards bodies (see Schmidt and Werle, 1998 for a more in-depth discussion of decisional processes in standardisation committees, and Funk, 2002, for a extensive treatment of competition between and within standards in the field of mobile telephony). The way in which the work on a new standard commences differs between standards bodies, but often it is triggered by a proposal that is backed by a number of members. A set of requirements is defined in order to establish the mandate of the participants (usually employees of member firms) that are going to make the standard (often called "Terms of Reference"). Subsequently, one or more Technical Committees are established in order to develop draft specifications for the standard. Members can decide to participate in these committees (by sending their representatives to the meetings, or even by providing the chairman) and, in this way, can take an active part in determining the exact technological content of the standard. Although higher bodies in the standards bodies (such as a General or a Technical Assembly, depending on the standards body) will still need to vote on the acceptance of a standard, the real technical inclusion process - including decisions to incorporate patented technologies - usually takes place in the Technical Committees. In exceptional cases, major design decisions might be taken to a higher level, but once these decisions are made, the detailed work goes back to the Technical Committee. In these committees, discussions and negotiations are going on about the exact definition of the standard, and therefore the exact set of technologies the standard is drawing on. In a continuous process, participants in these meetings propose all sorts of solutions and technologies in order to draft a standard that meets the set of requirements. If firms suggest technologies which they know are covered by patents - in particular their own patents - they are obliged to disclose this information. On the basis of the pursuit of consensus (which does not mean all need to agree, but is usually defined as the absence of persistent resistance), the committee makes decisions on whether to include suggested technologies. On some major decisions, standards bodies resort to formal voting procedures (that often require majority voting or 70\% majority voting), but many (smaller) technology decisions are made as a part of continuous negotiation processes in relatively small groups, where the participants usually know and respect each other very well and quite often see each other as friends. The benefits that firms derive from their inclusion in the social network created by cooperation in the standard has been found to be one of the strongest determinants of the willingness of firms to contribute to standards by participating in Technical Committees (Bar and Leiponen, 2008). In such a context, there might be a tendency to accept others bringing in their patented technologies, as long as you are allowed to do the same thing. In this way, the interests of all parties - or at least, of all the participants - are catered for. This 'technology inclusion' process offers firms a number of opportunities to drive patents into a standard. Both the specific, strategic behaviour of firms in Technical Committees as well as the use of voting power with strategic intend require a certain degree of involvement in the standardisation process. Hence our second hypothesis:

Hypothesis 2. The active involvement of the holder of a patent in the standards' creation process increases the likelihood of that patent being claimed essential to a standard.

Once the standard is established, firms may adopt a diverse set of further strategies for exploiting these patents and obtaining access to other parties' patents, where necessary. While our paper does not aim to explore this in great depth, it is worth noting that this process often involves the creation of larger portfolios of both essential and non-essential patents (where the value of some of the latter is often greatly overlooked), cross-licensing involving bundles of both essential and non-essential patents, and sometimes even patents for entirely different products, agreements on future patents, etc. 
Firm strategies for patents in standards receive increasing interest in the academic community, including contributions from Lemley (2002), Chiao et al. (2007), and Simcoe et al. (2009). The effects of 'royalty stacking' are discussed by Shapiro (2001) and Lemley and Shapiro (2006), and are critically commented on by Geradin et al. (2008). Considerable attention is paid to some strategies at the extreme end of the spectrum, such as 'holdup', patent ambush (see, for instance, Farrell et al., 2007 and Sidak, 2009), and patent trolls (Reitzig et al., 2007). Others have also claimed that firms massively 'over-claim' patents, i.e. unjustly declare patents to be essential (Goodman and Myers, 2005). While it may be attractive to do so in order to raise licensing revenues, at the same time, firms are expected to respect the IPR policies of standards bodies in letter and in spirit and claim their patents to be essential only when they are actually so. Claiming non-essential patents might lead to penalties when such patents are challenged in court and might eventually endanger the licensing income by all licensees.

\subsection{Research question and our approach}

The two preceding sections outline two basic determinants that may be significant when claiming a patent "essential" for a standard, namely: (1) the intrinsic value of the technological solution contained in the patent, (2) the involvement of the patents' owner in the creating of the standard, providing room for strategic conduct such as influencing the standards' content into the 'direction' of the patents of the firm. This paper aims to provide a detailed assessment of the role played by these two types of determinants. In order to do so, we analyse a set of patents that has been declared by their holders as being essential to the W-CDMA standard for mobile telephony/telecommunications. In order to identify the determinants affecting the probability of patents being claimed essential, we have constructed a set of (non-essential) control patents that mirrors our essential patents in both technical subject and distribution over time. Following Hegde et al. (2007), who applied this approach to study the determinants of the decisions of firms whether to apply for a continuation patent, we use a binomial logit model for assessing the determinants of essentiality declaration decisions.

\section{Data: the case of W-CDMA}

The W-CDMA standard is a third-generation (3G) standard for mobile telecommunications. It was designed as a successor to the successful, second-generation GSM standard. In addition to lowering the costs per call in comparison with earlier systems, WCDMA was also designed to support multimedia mobile phones that can accommodate web-based applications and offer phonebased audio and video facilities. This required not only much higher transmission speeds than in earlier generations but also much more flexibility: different users might require totally different speeds, and the speeds demanded by a given user may change a lot over time. To meet these requirements, new radio technologies had to be developed. Furthermore, the transition from second generation $(2 \mathrm{G})$ to third-generation (3G) technologies was much more than a technology upgrade, it also required a reconfiguration of the whole value network (Tilson and Lyytinen, 2006), which also affected the standardisation process.

The first research and standardisation activities for a European third-generation standard commenced in the early 1990s, even before the first commercial GSM network was launched. ${ }^{2}$ Several research programmes funded by the European Commission studied suitable radio technologies, and one of these (in earlier stages

2 This section does provide some references, but for a more extensive overview of the development and for a detailed list of references we refer to Bekkers (2001). known as 'CoDIT' and 'FRAMES FMA2') formed the basis for what eventually became W-CDMA. However, the 3G developments were largely ignored by GSM operators, who were focusing on increasing subscribers to their existing 2G systems (Garrard, 1998, pp. 478). In 1997, Japan, whose first and second generation standards had never achieved any success outside its domestic market and whose manufacturers had only a minimal role in supplying GSM products, attempted to leapfrog the other world regions by swiftly adopting a $3 \mathrm{G}$ standard and contracting both Japanese and other manufacturers to build test systems. In fact, the Japanese standards body ARIB specified a technology that was largely based on the outcome of the European FMA2 research programme. Japan's largest operator NTT DoCoMo not only ordered its experimental network with Japanese companies such as NEC, Fujitsu, Matsushita and Mitsubishi but also engaged non-Japanese firms, including Ericsson, Nokia, Motorola, and Lucent. By involving foreign suppliers, it tried to increase its chances of having the W-CDMA technology adopted in other world regions. The Japanese moves prompted Europe to speed up its process. Technical proposals by participants were clustered into five 'concept groups', of which the so-called alpha proposal and the delta proposal were regarded as the two most promising ones. The first was based largely identical to the technology selected by Japan and supported by Nokia and Ericsson, among others, whereas the latter was backed by Alcatel and Siemens, who were not involved in the Japanese activities at that point in time. In early 1998, in what turned out to be the most difficult and controversial decision process ETSI ever experienced, the alpha proposal came out as the winner. Soon after, ETSI agreed with the Japanese standards body ARIB and several other telecom standards bodies from other countries to align their efforts to ensure their $3 \mathrm{G}$ standard would be compatible, and the 3GPP partnership project was born. The resulting standard is known as W-CDMA, but within Europe is also referred to as UMTS and in Japan as FOMA (Freedom of Mobile Multimedia Access). Typically, W-CDMA is implemented in combination with GSM, its successor and the most successful generation mobile standard. W-CDMA is the most successful 3G standard, but not the only one. One competing technology is called cdma2000. It provides full backward compatibility with the second-generation cdmaOne standard, and for that reason it is mostly implemented in countries that applied its predecessor, particularly South-Korea and the United States (Lee et al., 2009). Its overall success, however, is limited. A third competitor is Time Division Synchronous Code Division Multiple Access (TD-SCDMA), developed in China with the help of some international companies like Siemens. The future success of this standard is unclear, and is likely to be limited to China itself at best.

For various reasons, W-CDMA is a particularly attractive case for assessing the determinants of essential patents in compatibility standards. First of all, it is a standard with a major economic relevance. The worldwide market for mobile telephony as of September 2010 amounted to just above 5 billion subscribers, ${ }^{3}$ The World Bank estimates a global telecommunications spending of about $2.5 \%$ of global GDP in 1990 (Insight Research Corporation, 2009). Although these phones do not yet all support W-CDMA, their share in Europe is already around 70\% and growing quickly (IDATE, 2007). Secondly, $\mathrm{W}$-CDMA is an attractive case because in order to meet the design requirements, it included a number of radical technological solutions, representing a new technological trajectory in the area of telecommunications. Finally, and possibly most importantly, there is a large and complete database publicly available of firms' declarations indicating which of their own patents they consider essential to $\mathrm{W}$-CDMA. The availability of such data is a relatively rare occur-

\footnotetext{
${ }^{3}$ Source: http://www.4gamericas.org, at 'statistics', consulted on January 24 2011.
} 
rence in this field. For all these reasons, the W-CDMA case seems an almost ideal test bed for assessing the determinants of essential patents.

\subsection{Data sources}

In this study we use the latest available data set containing all patents declared by their owners as essential to the W-CDMA standard. A database of all these declarations is made available online by $\mathrm{ETSI}^{4}$; we retrieved the relevant declaration in March 2008. These declarations are sent to ETSI by its individual members. As a matter of principle, ETSI is not responsible for judging these claims. In other words, to be included in the database there is no assessment of the "essential" nature of the content of these patents for W-CDMA technology. The database contains information on the patent owner, patent title, patent and application number, the standard and part of the standard the patent related to, and the country of registration. However, the data and in particular the consistency of its format, leave much to be desired (ETSI has currently embarked on a program to improve that). Since ETSI does not check this database for errors or duplicates, an extensive cleaning and sorting procedure is necessary to prepare the database for this study. The database we used was updated by ETSI in March 2008, and it contains 18,738 patents. 7090 patents are essential to standards that are not relevant for our research, for example GSM. Our selection of essential patents is restricted to those patents belonging to projects related to W-CDMA. Withdrawn and inactive patents ( 88 in total) have been deleted from the selection. We continued with all patents for which we could identify a US patent number, assuming that firms would at least seek to have a patent in this important market.

The US patent application numbers from the ETSI database were matched with the 'NBER Patent Citation Data File' compiled by Brownie Hall and her co-workers (Hall et al., 2001). The original NBER (National Bureau of Economic Research) data set comprises detailed information on almost 3 million U.S. patents granted between January 1963 and December 1999 and all citations made to these patents between 1975 and 1999 (over 16 million). In this study we use an updated version of the NBER data file constructed by Bart Verspagen (see Fontana et al., 2009 for another study employing this updated version). This updated version contains patents granted up to the year 2003, including citations pairs. In this way it was possible to retrieve the patent information included in the NBER database (inventor, applicant, title, primary USPTO class, citations, etc.) concerning 752 US patents that have been declared essential for the W-CDMA standard. The ETSI data set also contains patents registered in different countries and patent offices, but in this study we only use the USPTO patents. The reason for this choice is that US patent citations are probably more representative of the value of the patent, because in the US system, an applicant has a legal obligation to cite all relevant patents and prior knowledge ('duty of candor'). If a patent applicant fails to cite relevant patents, it risks to be sued. In Europe, patent citation is more or less voluntary; an applicant cannot be punished for not citing relevant patents (Criscuolo and Verspagen, 2008). As mentioned above, a number of studies such as Carpenter et al. (1981), Trajtenberg (1990) and Albert et al. (1991) have established that forward citations may be regarded as a valid proxy for the value of patents in the US. In order to compare essential W-CDMA patents with non-essential patents, we constructed a control set of comparable patents that are not claimed to be essential to W-CDMA. This is a sampled set where

\footnotetext{
${ }^{4}$ An on-line version of the ETSI IPR database can be found at http://webapp.etsi.org/ipr/.
}

patents are randomly selected from a defined population. ${ }^{5}$ These patents are also matched with the NBER US Patent Citation Data File. In order to make the non-essential patents comparable to the essential patents we have established a number of requirements that the random selection queries procedures had to satisfy. Firstly, the patents in the control data set should obviously not occur in the list of essential W-CDMA patents, since we do not want any essential patents in the control data set. ${ }^{6}$ Secondly, the distribution of patents over patent classes in the control class must be similar to the distribution of the original set of essential patents (here, we only included those classes with a share of $3 \%$ or higher). This ensures that essential W-CDMA patents are compared with a control set of non-essential patents covering the same technical fields. Finally, the essential and non-essential patent set must cover the same time-periods in terms of application year. Since the oldest essential patents were applied for in 1979, the patents in the control data set were retrieved from the period 1979-2003. Following these procedures, we have constructed a control group of about 10,000 non-essential telecom patents. Table 1 shows the patent classes with shares higher than $3 \%$ in the essential patents group and the corresponding shares in the randomly extracted control group of non-essential patents. Our variable of interest is constructed as a dummy distinguishing essential from non-essential patents $(0=$ non-essential, $1=$ essential $)$. The forward citations variable plays a key role in this study, as it represents our indicator of the technological importance of each patent (Hegde et al., 2007). As mentioned in the previous section, we follow an established line of research relying on a number of studies that have established the existence of a positive correlation between forward citations and technological importance. With technological importance we mean the value (or 'merit') of the technological solution described in the patent for the technological field in question. We should note that the number of forward citations is not a good measure of technological importance when comparing patents of different ages. Clearly, older patents had more opportunities of receiving citations than newer patents, so they will typically have a higher number of forward citations. This problem is aggravated by possible changes in patent and citation practices over time, which may have repercussions on the number of forward citations (Hall et al., 2001, pp. 434-437). In order to deal with this issue, we carried out a "fixed-effect" adjustment of the number of forward citations by dividing the number of forward citations of each individual patent with the average number of forward citations of patents of the same application year. In this way, we have constructed an indicator of technological importance that can be used for comparing patents of different ages (Hall et al., 2001, pp. 437-441).

Since we use received citations as our indicator of the intrinsic technological significance of the patent, it is important to consider to what extent a patent could actually receive (more) citations

\footnotetext{
5 The sample of 10,000 control patents is drawn from the population of all patents in the six patent classes that contain $90 \%$ of all patents claimed essential to the $\mathrm{W}$ CDMA standard (see Table 1 for a specification of these classes). For the selection we only considered those patents that fall in the same time frame as that of our essential patents (1979-2003). The patents were randomly selected using the random selection function in a database application (we used Microsoft Access for this). In order to prevent the extraction of duplicate patents, the essential W-CDMA patents were removed from the population before the random sampling procedure.

6 We should note that as information on essential patents is scarce, incomplete, and resource-consuming to collect, we cannot prevent that patents essential for other standards than W-CDMA are included in the control data set. This problem, however, should not introduce a major bias in our results as the random query procedure has been applied to a very large patent population. A reasonable upper bound estimate of essential patents for mobile telecom patents not claimed for W-CDMA is approximately 2000 patents. Thus, we have an average upper bound probability of about $2 \%$ ( 2000 out of 88,507$)$ that a patent in our control set would have been claimed essential in a non-W-CDMA standard.
} 
Table 1

Comparison of the distribution of USPTO technical classes across W-CDMA essential patents and across the sampled control croup.

\begin{tabular}{|c|c|c|c|c|}
\hline Primary class no. & Primary class title & Patents in primary class & $\begin{array}{l}\text { Claimed essential patents in } \\
\text { data set }(\%)\end{array}$ & $\begin{array}{l}\text { Non-essential patents in } \\
\text { sampled control group (\%) }\end{array}$ \\
\hline 370 & Multiplex communication & 20,831 & $225(30 \%)$ & $3,194(33 \%)$ \\
\hline 455 & Telecommunications & 18,340 & $193(26 \%)$ & $2,716(29 \%)$ \\
\hline 375 & $\begin{array}{l}\text { Pulse or digital } \\
\text { communications }\end{array}$ & 16,863 & $144(19 \%)$ & $2,045(21 \%)$ \\
\hline 704 & $\begin{array}{l}\text { Data processing: speech signal } \\
\text { processing, linguistics, } \\
\text { language translation, and audio } \\
\text { compression/decompression }\end{array}$ & 6,197 & $48(7 \%)$ & $679(7 \%)$ \\
\hline 714 & $\begin{array}{l}\text { Error detection/correction and } \\
\text { Fault detection/recovery }\end{array}$ & 13,842 & $33(4 \%)$ & $469(5 \%)$ \\
\hline 342 & $\begin{array}{l}\text { Communications: directive } \\
\text { radio wave systems and } \\
\text { devices (e.g., radar, radio } \\
\text { navigation) }\end{array}$ & 12,434 & $32(4 \%)$ & $459(5 \%)$ \\
\hline \multirow[t]{2}{*}{ Other } & & $\mathrm{n} / \mathrm{a}$ & $77(10 \%)$ & $0(0 \%)$ \\
\hline & & 88,507 & $752(100 \%)$ & $9,562(100 \%)$ \\
\hline
\end{tabular}

because of the fact that it is claimed to be essential. Overall, we believe this is not a major concern in our case. The concern that a patent may receive citations just because it was claimed as essential (independently from its intrinsic value) is implicitly based on a set of very specific assumptions: (i) the holder of the later (citing) patent is aware of the existence of the focal patent, (ii) he is aware that the focal patent is essential or likely to be essential and (ii) believes it is in its own interest to cite the focal patent. Concerning (i), we perform our calculations based on application year. It typically takes a year or more before a patent application becomes public and before a patent is granted (if at all). Also note that the USPTO system only allows citations to granted patents. Then, if the applicant of that later patent decides to cite the focal patent, it will take some time before this later (citing) is granted and some more time before it will appear in the database we have used to calculate the citations received. This delay limits the aforementioned risks for the patents applied for in the later years of our database. (Note that we consider all incoming citations from patents up to the year 2003). Concerning (ii), it is important to understand at what point in time parties could be aware that a certain patent would eventually be claimed essential for the standard. For W-CDMA, there was no way to tell which basic technologies would become relevant or not until the landmark basic technology decision in early 1998. Before that moment, totally different designs were in the race: not only CDMA-based but also based on ODFM and completely different basic technologies. (In fact, about a decade later, ODFM would be selected as the basis for W-CDMA its successor, dubbed LTE - but that goes beyond our story.) Although firms may have speculated about some 'basic technology' patents to become essential, they could not have known for sure until the official standard was decided upon and published (for W-CDMA, the first release called 'Release-99' was published in March 2000). Furthermore, even when both patent and standard are published, it can be surprisingly hard to assess whether a certain patent is indeed essential-this requires the production of a 'claim chart' where each claim of the patent is meticulously compared with all the specifications of the standard, sometimes 10,000 of pages. Only when a firm declares a patent to be essential, and this claim is added to the public database, other firms have good information about claimed essentiality. In the context of this study, it is important to note that there is a considerable delay for declaring patents. In our data set, the average time between the patent application and the moment the essentiality claim was sent to ETSI is seven years. For 'old' patents this is obvious: a patent filed back in 1980 cannot be declared being essential before the definitive standard is officially published in 1999, so the delay will be at least 19 years. However, the data reveals that there is also a considerable delay for more recent patents (Table 2 ). For instance, patents that were applied for in 1997 (and presumably are granted in 1998 or 1999), still have an average time lag of seven years before declaration (i.e. the claims arrived in 2004, on average). We conclude that in our particular data set, and the time period for which we considered incoming citations, there is only a very low chance that knowledge of patent essentiality may have affected the decision to cite essential patents.

Concerning (iii), we would like to emphasise that companies need to make careful considerations before citing an existing patent in a patent application at the US Patent Office, having to meet the 'duty of candor' obligation in US patent law (Section 1.56, Chapter 37 of the Code of Federal Regulations). By including a citation, an applicant confirms the existence of prior art and thereby limits the scope - and value - of its own patent. (On the other hand, failing to cite a relevant existing patent increases the risk of a patent being invalidated at a later date.) Patent examiners may also add citations that they believe to be missing from the application. Thus, citations have substantial legal consequences and are not added in the way that citations are added to academic papers, for instance.

Table 2

Average delay between patent application and declaration at ETSI.

\begin{tabular}{|c|c|c|c|c|c|}
\hline Application year & Patents & Average delay (years) & Application year & Patents & Average delay (years) \\
\hline 1981 & 1 & 21.00 & 1992 & 27 & 9.33 \\
\hline 1982 & 1 & 21.00 & 1993 & 44 & 8.77 \\
\hline 1983 & 2 & 20.50 & 1994 & 72 & 7.86 \\
\hline 1984 & 1 & 18.00 & 1995 & 69 & 7.54 \\
\hline 1985 & 3 & 18.00 & 1996 & 80 & 7.06 \\
\hline 1986 & 7 & 16.71 & 1997 & 92 & 6.35 \\
\hline 1987 & 9 & 15.56 & 1998 & 104 & 5.38 \\
\hline 1988 & 9 & 15.33 & 1999 & 91 & 4.85 \\
\hline 1989 & 10 & 12.50 & 2000 & 41 & 4.27 \\
\hline 1990 & 21 & 11.33 & 2001 & 22 & 3.77 \\
\hline 1991 & 30 & 9.30 & 2002 & 31 & 2.19 \\
\hline
\end{tabular}


Table 3

Descriptive statistics.

\begin{tabular}{|c|c|c|c|c|c|}
\hline Variables & Observations & Mean & Std. dev. & Min & Max \\
\hline Essential & 10,311 & 0.072 & 0.260 & 0.000 & 1.000 \\
\hline Forward citations & 10,311 & 9.444 & 20.153 & 0.000 & 617.000 \\
\hline Adjusted forward citations & 10,311 & 1.003 & 2.137 & 0.000 & 70.111 \\
\hline Total patents & 10,311 & 14989.500 & 15308.510 & 1.000 & 53595.000 \\
\hline Technological concentration (Herfindahl) & 10,311 & 0.120 & 0.188 & 0.011 & 1.000 \\
\hline Work items supported & 10,311 & 7.481 & 11.190 & 0.000 & 34.000 \\
\hline Voting weight & 10,311 & 12.413 & 15.876 & 0.000 & 45.000 \\
\hline R\&D expenditures ( $\times$ US\$1000) & 7,529 & 3758.062 & 6764.148 & 0.650 & 25471.930 \\
\hline Sales Turnover $(\times$ US $\$ 1000)$ & 7,692 & 36271.400 & 49172.590 & 0.000 & 171607.400 \\
\hline Employees $(\times 1000)$ & 5,824 & 123.226 & 111.314 & 0.000 & 468.200 \\
\hline
\end{tabular}

Continuing with our data set, we have also matched the applicant names of our patent data set with the names of companies in the Compustat database. ${ }^{7}$ Our original patent data set contained 2718 different company names as applicants. By means of extensive manual research on a number of internet sources such as the United States Securities and Exchange Commission website and on Compustat, we retrieved information on ownership structure and assigned patents applied by "daughters" to their respective "mother" companies. In this way we reduced our applicant set to 1850 different companies. Concerning mergers and acquisitions, we have taken 1999 as reference point: companies which merged before that year were considered one company, companies which merged after that year were added as two different companies in our data set. This is not likely to impact greatly on our results. From Compustat we then retrieved data on the annual average number of employees, the average sales turnover and the average R\&D expenditures over the period 1997-2001 for the companies included in our applicant set. As much as possible, all the additional data we collected refers to the 1999/2000 time frame, the period in which the standard was finalised.

In order to capture the strategic involvement of companies in the standardisation, we have constructed two additional variables. The first variable we apply is a proxy for the involvement of firms in actual drafting of the content of a specific standard. In 3GPP, new features, or work items, are proposed, accepted, developed, and certified if at least four firms support this work. Once a work item is under way, the supporting companies are expected to "contribute to and progress the new work item throughout the drafting phases" (Bar and Leiponen, 2008). As such, the number of work items within 3GPP supported by a given firm, as registered by 3GPP, reflects the actual degree of participation of companies in the development of new work. This data has been collected by Bar and Leiponen (2008), who also describe the underlying 3GPP procedures with project coordination groups, technical specification groups, working groups, and work items. Of the over 300 firms that were 3GPP members in 2000 , only 58 supported one or more work items. However, we should note that while the voting weight reflects the more "institutional" role of companies in the standardisation process, the number of work items supported probably reflects a more "active" degree of participation in the process possibly also because of genuine technological capabilities of the different companies in the areas in question. The second variable measuring involvement is the voting weight in the standardisation process. Voting weights are assigned to companies in relation to the contribution fees to ETSI. In turn, these are based on companies' declarations of their telecommunication-related revenues. Voting weights are assigned in units and can range from 1 to 45 . Appendix A contains a table with contributing fees and voting weights in ETSI. To summarise, at the end of our data construction efforts, we have a data set containing

\footnotetext{
7 For details on the contents of this see http://www.compustat.com.
}

10,314 USPTO patents, including 752 patents that are claimed to be essential for W-CDMA. For each of these patents we have proxies for value (captured by the adjusted number of forward citations) and for the strategic involvement of the patent owner in the standardisation process as captured by voting weights within ETSI or by the number of work items supported. Concerning the applicants, we have 1850 firms in our data set, while the essential patents are owned by 50 firms.

\subsection{Descriptive statistics}

Table 3 shows the descriptive statistics for the most important variables of our data set. Essential is the binary variable that distinguishes essential from non-essential patents. The mean is obviously relatively low, because the data set contains roughly ten times as many non-essential patents as essential patents. Firms that are not an ETSI member have no voting weight within ETSI whereas the maximum voting weight is 45 . The maximum number of 3GPP work items supported by a firm is 34 (Ericsson), while the minimum is zero. Ericsson is also the company with the highest net income. Most patents have zero forward citations, while USPTO patent 5,103,459 has the highest number of forward citations (617). This essential patent is owned by Qualcomm and the title is "System and Method for Generating Signal Waveforms in a CDMA Cellular Telephone System". A perusal of the patent reveals that this is likely to be the key technology for CDMA. Qualcomm is also the firm with the most essential patents (208). The highest value for the fixedeffect adjustment of forward citations of an individual patent by division with the yearly average is 70.1111 (variable adjusted forward citations). We have used two variables for characterising the patent portfolio of the patent owners. The first is the total number of US patents owned, whereas the second is the Herfindahl concentration index, indicating the degree of concentration of the firm's patent portfolio over the US primary patent classes. Finally we have variables measuring the size of the companies (employees and sales turnover) and the R\&D expenditures.

Fig. 1 shows the 12 firms with the highest number of claimed essential W-CDMA patents. The US-based firm Qualcomm owns 208 essential W-CDMA patents, which is more than $25 \%$ of all patents declared to the standard. Qualcomm is the original developer of Code Division Multiple Access (CDMA) technology for mobile telecommunications networks. The implementation of a W-CDMA air interface in the W-CDMA standard accounts for Qualcomm's high number of essential patents (Bekkers and West, 2009). The Swedish company Ericsson is in second place with 155 patents. Its core business moved from the production of mobile phones in the 1990s to the development and production of the cellular infrastructure. The third place ( 94 patents) is held by Interdigital, another US-based firm.

There are two aspects that set the companies Qualcomm and Interdigital apart from the other large owners of essential patents. In the case of Qualcomm, technology development and licensing is 


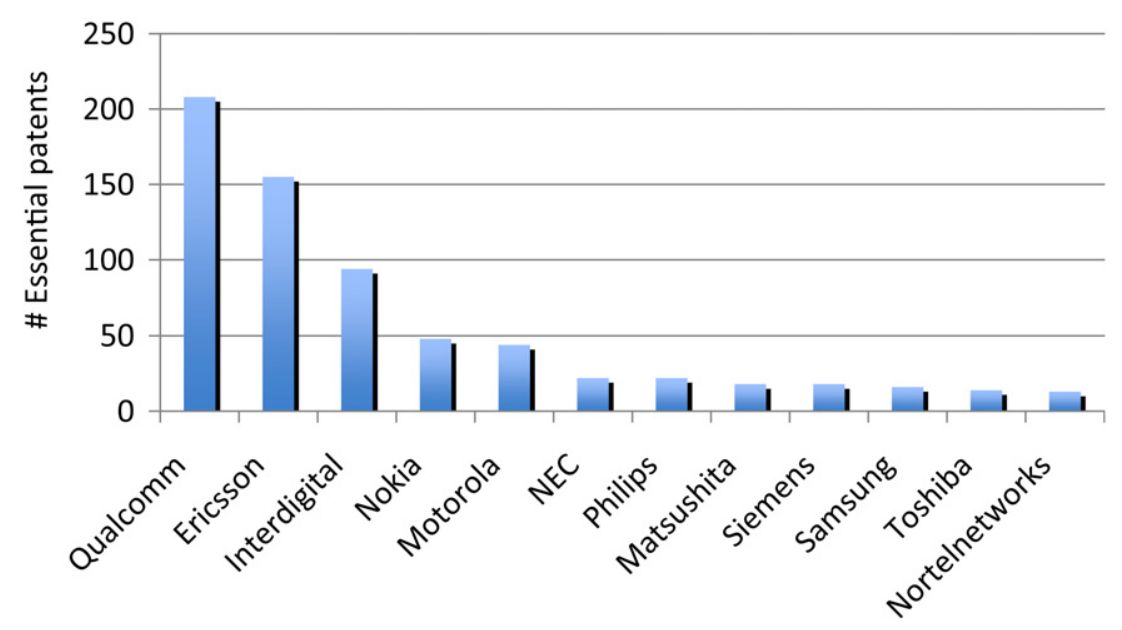

Fig. 1. Essential W-CDMA patent owners, 12 largest claimants.

Table 4

Propensity to claim patents as essential, 12 largest firms.

\begin{tabular}{|c|c|c|c|}
\hline Firm & USPTO patents claimed to be essential (our database) & Total patent stock in relevant subclasses & Ratio \\
\hline Qualcomm & 208 & 795 & $26.16 \%$ \\
\hline Ericsson & 155 & 3033 & $5.11 \%$ \\
\hline Interdigital & 94 & 219 & $42.92 \%$ \\
\hline Nokia & 48 & 1520 & $3.16 \%$ \\
\hline Motorola & 44 & 4254 & $1.03 \%$ \\
\hline Philips & 22 & 1791 & $1.23 \%$ \\
\hline NEC & 22 & 3567 & $0.62 \%$ \\
\hline Matsushita & 18 & 1382 & $1.30 \%$ \\
\hline Siemens & 18 & 1466 & $1.23 \%$ \\
\hline Samsung & 16 & 1023 & $1.56 \%$ \\
\hline Toshiba & 14 & 1131 & $1.24 \%$ \\
\hline Nortel networks & 13 & 1364 & $0.95 \%$ \\
\hline
\end{tabular}

a key element in its business model, although the firm also holds a strong position in the market for components for mobile phones. ${ }^{8}$ Interdigital is a non-producing entity (NPE) or 'technology-only' firm and has a business model that is almost entirely based on licensing its patented technologies to other firms in the telecom industry. We call these two firms 'technology specialists', to distinguish them from firms that are vertically integrated and primarily aim at competing in the product market for mobile telephones and mobile network infrastructure.

Table 4 examines the structure of the telecom patent portfolio of the companies owning the majority of W-CDMA essential patents. It shows the number of essential patents claimed by the twelve largest claimants, as well as the total number of patents of these firms in the technological classes relevant for the W-CDMA standard (Table 1). A third column shows the ratio between these two numbers. The table reveals that "technology specialists" such as Qualcomm and Interdigital own patent portfolios characterised by a relatively large share of claimed essential W-CDMA patents whereas the (often larger) vertically integrated firms have patent portfolios with smaller shares of claimed essential patents (the company with the largest share is Ericsson with a share of 5.11\%). Overall, the impression one gets from Table 4, is that essential patents play a key role in the technology strategies of "technology specialists". This is understandable if one realises that patents - and the associated royalty incomes - are key to the business models of

\footnotetext{
${ }^{8}$ Qualcomm has a 38\% revenue share in the global market for so-called baseband chipsets, the core component of a mobile phone in which the mobile telecommunications functionality is integrated. Source: The Free Library (March 15, 2010): "MediaTek unseats TI as No.2 cellular baseband chip vendor".
}

these firms, whereas for integrated firms, the freedom to operate on the product market is often more important.

The global market leader in producing cell phones, Nokia, is in fourth place with 48 essential patents. Fig. 2 shows the timing of patent applications for the five firms owning the highest number of essential W-CDMA patents. Qualcomm's series shows an early peak, which may be related to the development period of CDMA, which is the predecessor of the underlying air interface for W-CDMA.

Table 5 compares the technological importance of a firm's portfolio of essential patents with that of non-essential patents. The technological importance of a firm's patent portfolio has been computed as the average of the "fixed-effect" adjusted number of forward citations of the patents belonging to the firm's portfolio. Table 4 considers four different periods and contains the 14 firms with the most essential W-CDMA patents. The expectation that the technological importance of a firm's essential patent portfolio is higher than its non-essential patent portfolio is confirmed by these figures. Most of the average essential patent portfolios have an average citation ratio higher than 1 , while this value is lower than 1 for most of the non-essential patent portfolios. Siemens is the only firm where the technological importance of its essential patents is lower than 1 (which means that its essential patents have fewer forward citations than the yearly average). Siemens' essential W-CDMA patents have an average citation ratio of 0.84 . This might suggest that Siemens has used a suspicious patenting strategy for its W-CDMA patents, claiming patents of below average value as essential. However, we should note, as Table 4 indicates, that Siemens' non-essential patents are also of less importance. Another explanation for Siemens' low importance of essential WCDMA patents might be that Siemens was one of the firms that 


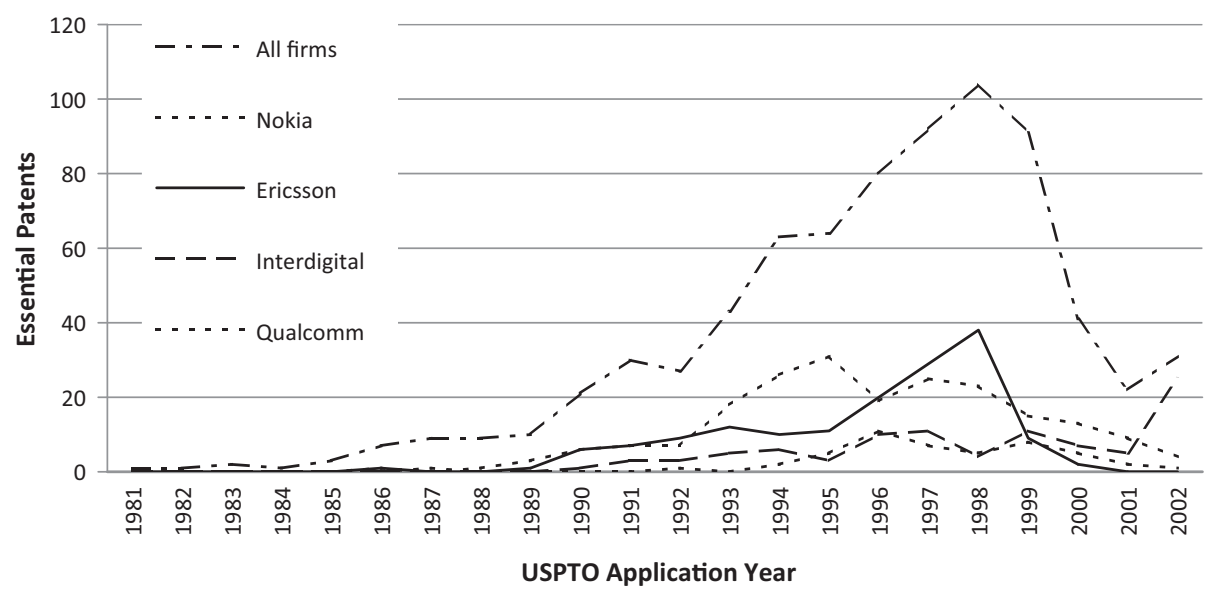

Fig. 2. Timing of essential patents by telecom market leaders.

Table 5

Average technological importance of firms' patent portfolio (USPTO patents).

\begin{tabular}{|c|c|c|c|c|c|c|c|c|}
\hline \multirow[t]{2}{*}{ Company name } & \multicolumn{4}{|c|}{ Patents claimed as essential } & \multicolumn{4}{|c|}{ Patents not claimed as essential (sampled control group) } \\
\hline & $1986-1990$ & 1991-1995 & 1996-2001 & All & $1986-1990$ & 1991-1995 & 1996-2001 & All \\
\hline Qualcomm & 10.27 & 3.01 & 2.98 & 3.21 & - & 1.36 & 1.38 & 1.32 \\
\hline Nokia & 3.14 & 1.15 & 1.28 & 1.21 & 1.74 & 1.00 & 1.05 & 1.05 \\
\hline Ericsson & 1.64 & 1.93 & 2.28 & 2.14 & 1.45 & 1.28 & 1.00 & 1.05 \\
\hline Interdigital & 4.44 & 1.77 & 1.35 & 1.46 & - & 0.79 & 0.46 & 0.59 \\
\hline Siemens & - & 0.67 & 0.84 & 0.84 & 0.33 & 0.52 & 0.60 & 0.56 \\
\hline Motorola & 4.25 & 1.62 & 1.29 & 2.25 & 1.10 & 0.79 & 0.95 & 0.94 \\
\hline Samsung & - & 0.79 & 1.80 & 1.74 & 0.27 & 0.83 & 0.56 & 0.57 \\
\hline Philips & 3.96 & 0.41 & 0.51 & 1.62 & 0.71 & 0.49 & 0.54 & 0.55 \\
\hline NEC & 3.90 & 0.43 & 2.76 & 2.31 & 0.66 & 0.59 & 0.43 & 0.56 \\
\hline Alcatel & - & 1.18 & 1.14 & 1.15 & 0.67 & 0.62 & 0.69 & 0.66 \\
\hline NTT & - & - & - & - & 1.09 & 0.96 & 1.30 & 1.11 \\
\hline Nortel & - & 0.76 & 3.10 & 2.71 & 1.09 & 1.15 & 1.12 & 1.12 \\
\hline Matsushita & - & 1.36 & 0.98 & 1.09 & 0.77 & 0.67 & 0.63 & 0.65 \\
\hline Toshiba & 0.89 & 0.56 & 0.00 & 0.71 & 0.54 & 0.77 & 0.96 & 0.80 \\
\hline
\end{tabular}

focused on the development of TD-SCDMA. Siemens, together with Alcatel, tried to convince ETSI to choose TD-SCDMA as the underlying air interface for the W-CDMA standard. So ETSI's choice for the competing W-CDMA technology in 1999 might be a reason for Siemens' low importance of essential W-CDMA patents.

Table 6 reports a preliminary assessment of the differences between the samples of essential and non-essential patents. Since our variables of interest (in particular the adjusted forward citations) are skewed and not normally distributed, we use a nonparametric Mann-Whitney test. Table 5 compares the adjusted number of forward citations, our proxy for the technological importance of the patent and work items supported and voting weight within ETSI, our proxies for the influence of a specific firm in the standardisation process for essential and non-essential patents. Interestingly enough, the Mann-Whitney tests in Table 5 indicate that essential patents are characterised by a significantly higher number of adjusted forward citations, and at the same time, are also owned by companies with higher voting weights or supporting more work items within ETSI. In other words, this preliminary evidence suggests that both the intrinsic technological value of the patent and strategic considerations by companies do play a role as determinants of essential patents.

\section{Multivariate analysis}

In this section we probe further into the possible determinants of essential patents estimating a number of logit regression mod- els. Our dependent variable is the dummy essential which equals ' 1 ' if the patent is claimed essential and equals ' 0 ' if the patent is not claimed as being essential. We estimate two sets of regression models. In the first set the variable capturing the role of strategic factors as determinant of the probability of a patent being claimed essential is the number of work items supported. In the second set we use the voting weight instead. In both cases the variable assessing the role of the intrinsic value of the patent is measured using the variable "adjusted forward citations". Since we are interested in comparing the relative effect of patent value with that of strategic factors, we estimate standardised coefficients which are obtained by normalising all the co-variates so that they have a mean of zero and standard deviation of one (Pampel, 2000). It is important to note that in all specifications, we introduce two dummy variables for controlling for patents owned by Qualcomm and Interdigital that, as we have seen in the previous section, are the two "technology specialists" companies owning patent portfolios characterised by relatively large shares of W-CDMA essential patents. Appendix $B$ presents the correlations between our variables.

Table 7 presents the results of the first set of regression models. In this set, adjusted forward citations and work items supported are the key variables of interest. The other co-variates are included as control variables. The coefficients for both adjusted forward citations and work items supported are positive and significant at $1 \%$ level in all regression models. Although the results show some differences in the estimated coefficients of these explanatory variables, overall they coefficients remain relatively stable across the 
Table 6

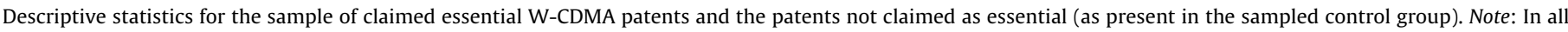
three cases the Mann-Whitney test rejects the hypothesis of equal populations $(p<1 \%)$.

\begin{tabular}{|c|c|c|c|c|c|c|c|}
\hline Variable & Sample/group & Observations & Mean & Median & Std. dev. & Min & Max \\
\hline \multirow[t]{2}{*}{ Adjusted forward citations } & Claimed essential & 691 & 2.242 & 1.394 & 3.098 & 0 & 35.055 \\
\hline & Not claimed essential & 8859 & 0.907 & 0.464 & 1.885 & 0 & 35.055 \\
\hline \multirow[t]{2}{*}{ Work items supported } & Claimed essential & 691 & 16.214 & 15.000 & 13.211 & 0 & 34.000 \\
\hline & Not claimed essential & 8859 & 7.279 & 0.000 & 10.975 & 0 & 34.000 \\
\hline \multirow[t]{2}{*}{ Voting weight } & Claimed essential & 691 & 27.852 & 30.000 & 16.095 & 0 & 45.000 \\
\hline & Not claimed essential & 8859 & 12.046 & 6.000 & 15.485 & 0 & 45.000 \\
\hline
\end{tabular}

different specifications. ${ }^{9}$ Furthermore, our results show that in all regression models the coefficient of the variable work items supported is higher than the coefficient of adjusted forward citations. This finding indicates that the influence of companies in the standards body exerts a greater impact than the technological value of the patent on the probability of the patent being claimed as essential.

It is worth discussing briefly the estimated coefficients of the control variables. As expected the sign of the two dummy variables controlling for Qualcomm and Interdigital are positive and significant. The coefficient of the Herfindahl Index (which is computed over the technological classes of the patent owner) is used here as a proxy for the technological diversity of firms and has a significant and positive influence on essential. This indicates that essential patents are much more often owned by firms whose patent portfolio is concentrated on one technology field, compared to non-essential patents. The dummy for Asia and Europe are positive and significant in all regressions indicating that patents owned by Asian and European companies have a higher probability of being claimed as essential for W-CDMA. Note, however, that this result is likely to be affected by the two dummies that control for the technology specialists companies.

The coefficient of the variable for R\&D expenditures is significant and positive in the model of column $2 .{ }^{10}$ Note instead that the two variables that we use to control for the size of the companies employees and sales turnover are significant with a negative sign. Again this result may be probably interpreted as an indication that the patents owned by companies with specialised patent portfolios in telecom, have higher probability to be claimed as essentials than rather than patents owned by large and diversified companies.

Table 8 presents six regression models where the two key explanatory variables of interest are adjusted forward citations and voting weight. We use voting weight as a proxy of dimension of involvement in the standardisation process and we are particularly interested in this set of regression, because as noted above, whereas the variable work items supported may be thought as reflecting also some technological competences, the variable voting weight probably captures more adequately the effect of the formalised institutional power of companies in the standardisation process. The coefficients of adjusted forward citations are fully in line with those estimated in the models in Table 7. Voting weight also has a significant and positive influence on essential. Again, in all the models estimated, the size of the standardised coefficient is higher than adjusted forward citations and this finding confirms the stronger role of the involvement with standards bodies as a deter-

\footnotetext{
${ }^{9}$ We obtain the same results concerning the different size of the two coefficients also estimating a similar set of models that do not control for the two "technology specialists" companies.

10 The first two columns contain control variables for firm size and R\&D expenditures extracted from the Compustat database. As this data could not be retrieved for all firms in our sample, these models are estimated on somewhat lower numbers of observations.
}

minant of the probability of a patent being claimed essential. ${ }^{11}$ Note also that the coefficient of the variable voting weight is in general higher than the corresponding coefficient for work items supported in Table 7. The results for the other control variables are fully consistent with those of Table 7. Also in this set of models, a smaller and more concentrated patent portfolio has a significant and positive effect. The regional dummies again reveal a higher probability of patents owned by European and Asian companies of being claimed essential. Finally, also in this set models, the variable for R\&D expenditures affects positively the probability that a patent is claimed as essential, whereas the variables controlling for size (employment and sales turnover) have a negative impact.

All in all, in both of our models, Hypothesis 1 and Hypothesis 2 are confirmed, and we show that the second one (patents are claimed essential because their owners participate in the standardisation process) is stronger than the first one (patents are claimed essential because of their high intrinsic value).

\section{Conclusion and discussion}

The question of what makes companies claim that their patents are essential for a technical standard is fascinating. If this is a result of the technical value of the patented technology (attributing value to the standard, such as increased performance, better costeffectiveness, etc.), there should be no concern. If non-producing firms would be licensing these patents for monetary return, and the compensation is in line with the technical value of the technology made available, then it would be a good example of the open innovation model as described by Chesbrough et al. (2008) and the markets for technology as suggested by Arora et al. (2004). However, if patents are claimed to be essential as a result of the strategic behaviour of the participants in standards bodies, but have no genuine technical value, we have a different story. It can be argued that this would be undesirable from a public welfare point of view and actually incompatible with the fundamental principles of standard creation as it would unnecessarily restrict access to standards, create barriers to their use and adoption, and increase their costs. Furthermore, such behaviour could unnecessarily complicate the standard from a technical point of view, a concern that was recently expressed by the chairman of ETSI's IPR Special Committee when he observed an increase of what he called 'marginal patents'. ${ }^{12}$

Our study on the determinants of essential patent claims shows that in the W-CDMA case, essential patent claims are both the result of intrinsic technical value ('merit') and of the involvement of their

\footnotetext{
11 Again, we obtain the same results concerning the different size of the two coefficients also estimating a similar set of models that do not control for the two "technology specialists" companies.

12 "[There is a] risk of complicating the solutions just for getting patented technology into the standard rather than to improve the standard." Dirk Weiler standards related patent Quality A view from a standardisation organization, EC/EPO Workshop on "Tensions between intellectual property rights and standardisation: reasons and remedies", Brussels, 22 November 2010. Available from http://ec.europa.eu/enterprise/sectors/ict/files/ict-policies/5_weiler_en.pdf.
} 
Table 7

Logistic regressions (standardised coefficients). Dependent variable is "Essential".

\begin{tabular}{|c|c|c|c|c|c|c|}
\hline & (1) & (2) & (3) & (4) & (5) & (6) \\
\hline Adjusted forward citations & $0.294^{* * *}(0.0415)$ & $0.320^{* * *}(0.0373)$ & $0.299^{* * *}(0.0319)$ & $0.283^{* * *}(0.0310)$ & $0.278^{* * *}(0.0310)$ & $0.278^{* * *}(0.0309)$ \\
\hline Work items supported & $0.567^{* * *}(0.125)$ & $0.661^{* * *}(0.0817)$ & $0.730^{* * * *}(0.0577)$ & $0.912^{* * * *}(0.0430)$ & $0.908^{* * * *}(0.0432)$ & $0.908^{* * * *}(0.0427)$ \\
\hline Application year & $-0.0125(0.0151)$ & $-0.0114(0.0129)$ & $-0.00332(0.0119)$ & $0.000533(0.0118)$ & $-0.000113(0.0116)$ & \\
\hline Total patents & $0.568^{* * * *}(0.169)$ & $0.515^{*+*+}(0.126)$ & $0.141^{* *}(0.0692)$ & $0.225^{* * t *}(0.0682)$ & & \\
\hline Technological concentration (Herf.) & $0.747^{* * *}(0.235)$ & $0.766^{* * *}(0.203)$ & $0.296^{* *}(0.122)$ & $0.391^{* * *}(0.106)$ & & \\
\hline Europe dummy & $0.743^{* * *}(0.190)$ & $0.977^{* * *}(0.188)$ & $1.008^{* * *}(0.158)$ & & & \\
\hline Asia dummy & $0.789^{* *}(0.375)$ & $0.156(0.227)$ & $0.696^{* * * *}(0.170)$ & & & \\
\hline$R \& D$ expenditures & $1.070(0.769)$ & $0.881^{* * * *}(0.263)$ & & & & \\
\hline Employees & $-0.552^{* * * *}(0.207)$ & & & & & \\
\hline Sales turnover & & $-0.943^{* * *}(0.330)$ & & & & \\
\hline Qualcomm dummy & $4.656^{* * *}(0.228)$ & $4.660^{* * *}(0.205)$ & $4.807^{* * * *}(0.179)$ & $4.444^{* * * *}(0.162)$ & $4.372^{* * * *}(0.153)$ & $4.372^{* * *}(0.151)$ \\
\hline Interdigital dummy & $4.032^{* * *}(0.412)$ & $3.912^{* * *}(0.360)$ & $4.362^{* * *}(0.301)$ & $3.758^{* * *}(0.277)$ & $3.999^{* * *}(0.255)$ & $3.999^{* * *}(0.254)$ \\
\hline Constant & $21.25(30.09)$ & $18.86(25.65)$ & $2.638(23.75)$ & $-4.603(23.58)$ & $-3.345(23.08)$ & $-3.571^{* * *}(0.0721)$ \\
\hline Observations & 5480 & 7363 & 9550 & 9550 & 9550 & 9550 \\
\hline Log-likelihood & -994.0 & -1441 & -1657 & -1681 & -1688 & -1688 \\
\hline Pseudo R2 & 0.379 & 0.342 & 0.332 & 0.322 & 0.319 & 0.319 \\
\hline
\end{tabular}

Standard errors in parenthesis.

"Significant at $10 \%$.

"*. Significant at $5 \%$.

Table 8

Logistic regressions (standardised coefficients). Dependent variable is "Essential".

\begin{tabular}{|c|c|c|c|c|c|c|}
\hline & (1) & (2) & (3) & $(4)$ & (5) & (6) \\
\hline Adjusted forward citations & $0.275^{* * *}(0.0425)$ & $0.308^{* * *}(0.0390)$ & $0.296^{* * *}(0.0332)$ & $0.284^{* * *}(0.0323)$ & $0.280^{* * *}(0.0321)$ & $0.281^{* * *}(0.0321)$ \\
\hline Voting weight & $0.524^{* * *}(0.138)$ & $0.809^{* * *}(0.111)$ & $0.949^{* * *}(0.0860)$ & $0.956^{* * *}(0.0468)$ & $0.939^{* * *}(0.0461)$ & $0.940^{* * *}(0.0457)$ \\
\hline Application year & $-0.0172(0.0151)$ & $-0.0126(0.0129)$ & $-0.000742(0.0120)$ & $0.00235(0.0119)$ & $0.00208(0.0117)$ & \\
\hline Total patents & $0.466^{* * *}(0.163)$ & $0.363^{* * * *}(0.110)$ & $0.177^{* 2 * t}(0.0666)$ & $0.234^{* * *}(0.0636)$ & & \\
\hline Technological concentration (Herf.) & $0.868^{* * *}(0.229)$ & $0.839^{* * *}(0.199)$ & $0.456^{* *+}(0.113)$ & $0.409^{* * * *}(0.106)$ & & \\
\hline Europe dummy & $0.450^{*}(0.246)$ & $0.189(0.230)$ & $0.455^{* *}(0.191)$ & & & \\
\hline Asia dummy & $1.486^{* * t+}(0.339)$ & $0.608^{* * * *}(0.228)$ & $0.886^{* *+1}(0.176)$ & & & \\
\hline$R \& D$ expenditures & $2.525^{* * *}(0.650)$ & $0.428^{* *}(0.208)$ & & & & \\
\hline Employees & $-0.687^{* * *}(0.217)$ & & & & & \\
\hline Sales turnover & & $-0.194(0.241)$ & & & & \\
\hline Qualcomm dummy & $4.178^{* * *}(0.283)$ & $3.650^{* 2 *}(0.213)$ & $3.502^{* * *}(0.192)$ & $3.171^{* * *}(0.149)$ & $3.102^{* * *}(0.140)$ & $3.104^{* * *}(0.140)$ \\
\hline Interdigital dummy & $4.916^{* * *}(0.400)$ & $4.853^{* * *}(0.366)$ & $5.247^{* * *}(0.296)$ & $4.971^{* * *}(0.287)$ & $5.196^{* * *}(0.266)$ & $5.201^{* * *}(0.265)$ \\
\hline Constant & $30.99(30.12)$ & $21.43(25.79)$ & $-2.425(23.86)$ & $-8.222(23.73)$ & $-7.690(23.30)$ & $-3.546^{* * *}(0.0718)$ \\
\hline Observations & 5,480 & 7,363 & 9,550 & 9,550 & 9,550 & 9,550 \\
\hline Log likelihood & -997.3 & -1446 & -1677 & -1691 & -1700 & -1700 \\
\hline Pseudo R2 & 0.377 & 0.339 & 0.324 & 0.318 & 0.315 & 0.315 \\
\hline
\end{tabular}

Standard errors in parenthesis.

Significant at $10 \%$.

" Significant at 5\%.

Significant at $1 \%$ 
holders in the standardisation process (creating room for strategic conduct). We observe, however, that the involvement in the process is a stronger determinant than the technical value of the patent. While our findings are in line with several other studies providing evidence of the existence of both effects, this study - to the best of our knowledge - is the first one that has considered both effects simultaneously.

Assuming that forward citations do reveal patent value, we conclude that technical value is a significant determinant of claims of essentiality. We find a positive, significant and robust relationship, and looking at the data, we indeed observe sets of patents with a higher than average value even though the owner (Qualcomm) was not actively participating in the standards body in question at the time the technology was determined. These patents obviously became essential by virtue of their technical value. (In fact, most of the different 3G candidate technologies put forward in 1999 relied on that same technology; see Bekkers (2001) for a detailed account.) If we remove the Qualcomm patents from our database, we see that the influence of the technical importance of patents on essentiality is reduced, while at the same time the remaining firms show an even stronger behaviour. So Qualcomm's patents are of high technical importance, and this firm was probably not behaving strategically in the standard setting process (in terms of the involvement we are capturing in our study). Assuming that the voting weight a firm has in the standards body, and the actual involvement in the standards drafting process (captured by registered 'work item support'), are both proxies of the opportunities for involvement and influencing the content of the standard, we conclude that strategic involvement is also a significant determinant of claims for essential items. Being an active member helps to get more essential patents. Furthermore the status of active member is found to be a stronger determinant than the technological value of the patent as captured by forward citations.

We will now further discuss the implications of these findings. Although previous studies on the era before the emergence of standards bodies have shown cases in which market access and firm performance was highly dictated by patent strategies of essential patent owners (Bekkers et al., 2002), it would be unreasonable to suggest such an effect in the current context where formal standards bodies have (F)RAND regimes. Also, we do observe significant changes in market share over time in the market we examine here: in the market for mobile terminals, the current number two and three position are for Samsung and LG, two South-Korean firms that were hardly active on the global market a decade ago, and the number two position in mobile infrastructure has recently been captured by a Chinese supplier, Huawei, whose global activities were negligible even shorter ago. Also Apple and Research in Motion (maker of the BlackBerry phone) are examples of successful new entrants, outside the set of 'incumbent champions'. However these considerations do not mean that ownership of essential patents is not extremely important in the telecom sector. While reliable data on actual licensing fees for specific technologies are hard to find, some parties have been claiming licensing fees of up to $30 \%$ for mobile devices, ${ }^{13}$ much more realistic estimates are given by a recent study commissioned by the European Commission (Interplay, 2010). Here, it is estimated that the aggregate licensing fees for firms implementing $\mathrm{W}$-CDMA phones is approximately

\footnotetext{
13 For GSM, the predecessor of W CDMA, the director of the European public Telecommunications Network Operators' association (ETNO) revealed that royalty fees make up $29 \%$ of the costs of GSM handsets (Taaffe, 2000). Some industry analysts claim that "Estimates for cumulative royalties for W CDMA are between $25 \%$ and $30 \%$ and the mobile industry could spend US\$80-100 billion on W CDMA-IP-royalty payments up to 2017" (Poropudas, T., 2006. ETSI moves to exclude Qualcomm. MobileMonday Global: Industry News, 1 March 2006).
}

$12 \%$ of the wholesale ('ex-works') value of these devices. Firms that have a reasonably strong patent portfolio themselves can negotiate cross-licenses and would typically be paying around $8 \%$ (which already signals the value of owning such patents). Also the high number of high-profile patent cases in this field signals the economic importance of these patents. These numbers illustrate the substantial sums of money involved and the possible distortion of the market if these sums are paid for patents that do not have actual technical value. In fact, it is likely that the pivotal monetary and strategic value associated with essential patents have contributed to trigger a number of high-profile legal cases and complaints to authorities, such as Qualcomm suing both Nokia and Broadcom for patent infringement in the US and the UK (including a complaint with the U.S. International Trade Commission), Nokia suing Interdigital in both the US and in the UK, six large firms filing a complaint against Qualcomm with the European Commission for excessive royalties (a case that was dropped later on), ${ }^{14}$ and, recently, Nokia filing a lawsuit against Apple in the US, arguing that the iPhone infringes on its essential patents, followed by a countersuit by Apple. $^{15}$

Having performed this analysis for one single standard, the question emerges how generalizable our results are. In general, we believe that our findings will hold for all technologies for which essential patents are claimed by their respective owners. This is certainly the case for technologies that are standardised in settings where a (F)RAND policy with declarations of essential patents applies. This includes virtually all formal standards bodies around the world. A recent study on patents in standards commissioned by the European Commission analysed eleven major formal standards bodies, and identified more than 200 standards for which patents were claimed (Interplay, 2010). The number of claimed patents for standards is very skewed, however. The report distinguishes four categories. The first, 'Telecom standards' includes seven standards that have (much) more than 100 patents claimed, and another 20 standards with less than 100 claimed patents. The second category, 'IT and consumer electronics', includes many picture, audio and video coding standards, and computer interfaces (e.g. FireWire). For most of these standards, between 20 and 100 patents are claimed. The third category, 'Enabling technologies', includes standards that are specifically designed for certain application areas. Here, the RFID standard has more than 100 claimed patents, many other standards have typically one to 20 patents claimed (one interesting example is 'agricultural electronics identification'. Finally, the category of 'Genuine non-ICT related standards' has few standards for which patents are claimed, and the number of patents for these standards is generally low. In addition to the formal standards bodies, many standard-developing fora and consortia have similar (F)RAND policies with declaration rules as well. Many technologies, particularly consumer electronics standards, have been developed in such settings. (Well-known pools are the two pools for DVD technologies and the pool for MPEG coding standards.) We expect that our finding will hold for such type of organisations as well. A specific category would be those standards for which patent pools are established. In order to comply with antitrust/competition laws, such pools virtually always include a procedure where candidate patents are thoroughly tested for essentiality, usually by an external evaluator. Because this limits the possibility of parties claiming non-essential patents to be essential we expect that, compared to our findings, technological value will prevail over strategic involve-

\footnotetext{
14 See Bloomberg. Qualcomm Antitrust Probe Is Dropped by EU Regulators. November $24,2009$.

15 See Financial Times, 22 October 2009, "Nokia takes on iPhone in legal fight", as well as The Economist (online edition, 23 October 2009), "Dial L for lawyer: A nasty legal spat among tech giants pits Nokia against Apple”.
} 
ment as a determinant in such a setting. Still, patent pools do not prevent that patents are included that have low technical value yet are indeed essential in a literal sense of the definition. A recent paper by Baron and Decamp showed that firms that are already member of the pool are indeed more able to include lower value patents than 'outsiders' (Baron and Delcamp, 2010). Finally, it should be stressed that any patent owner is free whether or not to join a pool, while such a freedom does not exist for participants in standardisation bodies when it comes to the IPR rules, which is something that might also affect the findings. Having indicated in which field we believe our findings would hold, we still believe it would be an obvious direction of further research to test other standards or technological fields.

Obviously, our study has some limitations. As already suggested above, we can only make claims about the specific case we discussed (although we indicated in which other situations the findings would hold). Also, patent citations are no perfect value indicators, and citations might be attracted because a patent is claimed as essential (we have limited that effect by truncating incoming citations after the first release of the standard was frozen). There is one more specific limitation we would like to mention here: there is one more mechanism that might lead to essential patent claims that is not studied in this paper. Since the process we study involves self-declarations, firms may deliberately claim certain patents as being essential even when they are aware this is not the case. Because it is quite hard to actually determine whether a certain patent is essential or not (this requires the development of a chart where each claim in the patent is held against each element of the standard), and because challenging such patents is an expensive and time-consuming activity that includes, some implementers rather just pay for a license, even when they have some doubts. At the same time, some more powerful players might refrain from paying a license, knowing that the patent owner rather enjoys the income from other licenses than risking losing an infringement case. While this mechanism certainly could explain a specific category of essential patent claims, we believe that there is no reliable data that would allow us to test for this.

Our work has also some policy implications. Although it would be an ungrounded assertion that patent claims are solely the result of strategic gaming, participants still systematically influence the content of the standard in the direction of their own patented technologies, valuable or not. Although it would be hard to imagine a world where such things do not take place at all, it may be argued that on the basis of welfare effects, society would benefit from a process with more feedback loops, where the technical inclusion of certain (patented) technologies in standards would result in a more transparent and open process. Current decisions concerning the inclusion of specific patents in a standard are made in relatively small technical groups, where it is likely (and perhaps unavoidable) that reciprocal favours are granted-e.g. if you allow me to include a trivial patent, I will allow you to do likewise. Standards bodies, as well as other stakeholders (such as the public authorities that recognise these bodies) would do well to study in detail the dynamics of these technical inclusion processes and consider possible reforms, for instance by introducing new incentives and safeguards. Other help could come from current efforts to allow the patent offices access to - now often confidential - documents at the time of the standardisation effort, improving their ability to determine the prior art and dismiss patent applications on inventions that are not novel. ${ }^{16}$ Finally, voluntary ex-ante licensing, a process whereby patent holders can choose to reveal their licensing conditions before the technology gets included, may help to promote more conscious technological inclusion discussions. While the successful introduction of such processes will certainly not be easy, and the discussions on this topic are surrounded by mutual incomprehension, the recent adoption of such procedures by the IEEE shows promise. A more far-reaching policy would be that for each known patent to be included, a formal assessment is performed about the alternatives and their relative costs and benefits (including nonpatented alternatives).

\section{Acknowledgements}

The authors would like to thank Aija Leiponen for making data available on the participation of companies in 3GPP working groups. We would like to thank the two anonymous referees for their valuable comments, as well as the participants of the DRUID 2009 Summer conference in Copenhagen and the 6th international conference on Standardization and Innovation in Information Technology (SIIT 2009) in Tokyo, where earlier versions of this paper were presented.

\section{Appendix A. ETSI annual contribution fees}

Source: ETSI website, 2008.

\begin{tabular}{lcc}
\hline $\begin{array}{l}\text { Electronics communications } \\
\text { related turn over (ECRT) in Euro }\end{array}$ & $\begin{array}{l}\text { Voting weight } \\
\text { ('units') }\end{array}$ & $\begin{array}{l}\text { Annual contribution } \\
\text { fee (Euro) }\end{array}$ \\
\hline $\begin{array}{l}\text { SMEs, user and trade associations, } \\
\text { additional membership }\end{array}$ & 1 & 6,000 \\
Micro-Enterprises & 1 & 3,000 \\
Universities, public research bodies & 1 & 2,000 \\
and not-for-profit user associations & & \\
Up to 135 million & 2 & 9,380 \\
136-200 million & 3 & 12,760 \\
201-450 million & 6 & 22,900 \\
451-700 million & 9 & 33,040 \\
701-1350 million & 13 & 46,560 \\
1351-2000 million & 18 & 63,460 \\
2001-3500 million & 24 & 83,740 \\
3501-5000 million & 30 & 104020 \\
5001-8000 million & 37 & 127,680 \\
Above 8000 million & 45 & 154,720 \\
\hline
\end{tabular}

\footnotetext{
${ }^{16}$ Such efforts were extensively discussed at a recent workshop of the European Commission and the European Patent Office (EPO): "Tensions between Intellectual Property Rights and the ICT standardisation process: reasons and remedies", held in Brussels on 22 November 2010.
} 
Appendix B. Correlations

\begin{tabular}{|c|c|c|c|c|c|c|c|c|c|c|c|}
\hline & 1 & 2 & 3 & 4 & 5 & 6 & 7 & 8 & 9 & 10 & 11 \\
\hline Essential & 1 & & & & & & & & & & \\
\hline $\begin{array}{l}\text { Adjusted } \\
\text { forward } \\
\text { citations }\end{array}$ & $0.15^{* * *}$ & 1 & & & & & & & & & \\
\hline Voting weight & $0.25^{* * *}$ & $0.04^{* * *}$ & 1 & & & & & & & & \\
\hline $\begin{array}{l}\text { Work items } \\
\text { supported }\end{array}$ & $0.21^{* * *}$ & $0.02^{* *}$ & $0.78^{* * *}$ & 1 & & & & & & & \\
\hline Total patents & $-0.07^{* * *}$ & $-0.06^{* * *}$ & $0.13^{* * *}$ & $0.11^{* * *}$ & 1 & & & & & & \\
\hline $\begin{array}{l}\text { Technological } \\
\text { concentration } \\
\text { (Herf.) }\end{array}$ & $0.08^{* * *}$ & $0.05^{* * *}$ & $-0.11^{* * *}$ & $-0.09^{* * *}$ & $-0.43^{* * *}$ & 1 & & & & & \\
\hline Employees & $-0.17^{* * *}$ & $-0.07^{* * *}$ & $0.03^{*}$ & $0.13^{* * *}$ & $0.77^{* * *}$ & $-0.50^{* * *}$ & 1 & & & & \\
\hline Net income & $0.10^{* * *}$ & $0.04^{* * *}$ & $0.45^{* * *}$ & $0.48^{* * *}$ & $0.08^{* * *}$ & $0.10^{* * *}$ & $0.47^{* * *}$ & 1 & & & \\
\hline $\begin{array}{l}\text { R\&D } \\
\text { expenditures }\end{array}$ & $0.14^{* * *}$ & $0.04^{* * *}$ & $0.61^{* * *}$ & $0.69^{* * *}$ & $-0.08^{* * *}$ & $0.15^{* * *}$ & $0.63^{* * *}$ & $0.81^{* * *}$ & 1 & & \\
\hline $\begin{array}{l}\text { Dummy } \\
\text { qualcomm }\end{array}$ & $0.41^{* * *}$ & $0.13^{* * *}$ & $0.19^{* * *}$ & $-0.04^{* * *}$ & $-0.14^{* * *}$ & $0.07^{* * *}$ & $-0.24^{* * *}$ & $-0.11^{* * *}$ & $-0.10^{* * *}$ & 1 & \\
\hline $\begin{array}{l}\text { Dummy } \\
\text { interdigital }\end{array}$ & $0.30^{* * *}$ & 0.01 & $-0.07^{* * *}$ & $0.07^{* * *}$ & $-0.10^{* * *}$ & $0.17^{* * *}$ & $-0.16^{* * *}$ & $-0.07^{* * *}$ & $-0.07^{* * *}$ & $-0.02^{* *}$ & 1 \\
\hline
\end{tabular}

* Significant at $10 \%$.

** Significant at $5 \%$.

**** Significant at $1 \%$.

\section{References}

Albert, M.B., et al., 1991. Direct validation of citation counts as indicators of industrially important patents. Research Policy 20, 251-259.

Andersen, P., 2008. Evaluation of Ten Standard Setting Organizations with Regard to Open Standards. IDC, Copenhagen, Denmark.

Arora, A., Fosfuri, A., Gambardella, A., 2004. Markets for Technology: The Economics of Innovation and Corporate Strategy. The MIT Press, Cambridge.

Bar, T., Leiponen, A., 2008. Collaboration and Networking in Cooperative Standard Setting. Paper presented at the 25th DRUID Celebration Conference, Copenhagen June 17-20, 2008.

Baron, J., Delcamp, H., 2010. Strategic inputs to patent pools. International Schumpeter Society Conference, 2010. Aalborg, June 21-24.

Bekkers, R., 2001. Mobile Telecommunications Standards: GSM, UMTS, TETRA and ERMES. Artech House, Boston, MA, USA.

Bekkers, R., West, J., 2009. The limits to IPR standardization policies as evidenced by strategic patenting in UMTS. Telecommunications Policy 33, 80-97.

Bekkers, R., Duysters, G., Verspagen, B., 2002. Intellectual property rights, strategic technology agreements and market structure-the case of GSM. Research Policy 31, 1141-1161.

Carpenter, M.P., Narin, F., Woolf, P., 1981. Citation rates to technologically important patents. World Patent Information 3, 160-163.

Chesbrough, H., Vanhaverbeke, W., West, J., 2008. Open Innovation: Researching a New Paradigm. Oxford University Press, Oxford, UK.

Chiao, B., Lerner, J., Tirole, J., 2007. The rules of standard-setting organizations: an empirical analysis. RAND Journal of Economics 38, 905-930.

Criscuolo, P., Verspagen, B., 2008. Does it matter where patent citations come from? Inventor vs. examiner citations in European patents. Research Policy 37, 1892-1908.

Farrell, J., 2007. Standard setting, patents, and hold-up. Antitrust Law Journal 74 603-670.

Fontana, R., Nuvolari, A., Verspagen, B., 2009. Mapping technological trajectories as patent citation networks. An application to data communication standards. Economics of Innovation and New Technology 18, 311-336.

Funk, J.L., 2002. Global Competition between and within Standards: The Case of Mobile Phones. Palgrave, Hampshire, UK.

Funk, J.L., Methe, D.T., 2001. Market-and committee-based mechanisms in the creation and diffusion of global industry standards: the case of mobile communication. Research Policy 30, 589-610.

Garrard, G.A., 1998. Cellular Communications: World-Wide Market Development. Artech House, Norwood, MA, USA.

Geradin, D., Layne-Farrar, A., Padilla, A.J., 2008. The complements problem within standard setting: assessing the evidence on royalty stacking. Boston University Journal of Science \& Technology 14 (2), 144-167.

Goodman, D.J., Myers, R.A., 2005. 3G Cellular standards and patents, 2005. IEEE Wireless Communications and Networking Conference, pp. 415-420.

Granstrand, O., 2005. Innovation and intellectual property rights. In: Fagerberg, J., D.C, M., Nelson, R.R. (Eds.), The Oxford Handbook of Innovation. Oxford University Press, Oxford, UK.

Hall, B.H., Jaffe, A.B., Trajtenberg, M., 2001. The NBER patent citations data file: lessons, insights and methodological tools. NBER Working Paper No. 8498.

Hegde, D., Mowery, D.C., Graham, S.J.H., 2007. Pioneers, submariners, or thicketbuilders: which firms use continuations in patenting? NBER Working Paper No. 13153.
IDATE, 2007. Development of Broadband Access in Europe: Methodological Report 2007 Survey Data as of 31 December 2006. DG Information Society, Brussels.

Insight Research Corporation, 2009. The 2009 Telecommunications Industry Review: An Anthology of Markets Facts and Forecasts. Insight Research Corporation, New Jersey.

Interplay consortium, 2010. Study on the interplay between standards and intellectual property rights (IPRs); Preliminary Results. Interim results of a study commissioned by the European Commission. Presented at the Open Workshop organized by DG Enterprise of the European Commission, November 23rd 2010.

Iversen, E., 1999. Standardisation and Intellectual Property Rights: ETSI's controversial search for new IPR-procedures. In: SIIT'99-IEEE Conference on Standardisation and Innovation, Aachen, Germany, pp. 15-17.

Krechmer, K., 1998. The principles of open standards. Standards Engineering 50 (6), $1-6$.

Krechmer, K., 2005. The meaning of open standards. In: Proceedings of the Annual Hawaii International Conference on System Sciences, Hawaii, p. 204.

Layne-Farrar, A. 2008. Innovative or Indefensible? An Empirical Assessment of Patenting within Standard Setting, Presented at the CEPR-Bank of Finland conference on Innovation and Intellectual Property in Finance.

Lee, B.G., et al., 2009. Technical innovation and 3.5 mobile phone generation: lessons from Korea. Telecommunications Policy 33, 296-308.

Lemley, M.A., 2002. Intellectual property rights and standard-setting organizations. California Law Review 90, 1889-1980.

Lemley, M.A., Shapiro, C., 2006. Patent holdup and royalty stacking. Texas Law Review 85, 1991-2049.

Pampel, F.C., 2000. Logistic Regression. A Primer. Sage, Thousands Oaks.

Reitzig, M., Henkel, J., Heath, C., 2007. On sharks, trolls, and their patent prey-unrealistic damage awards and firms' strategies of "being infringed". Research Policy 36, 134-154.

Rysman, M., Simcoe, T., Heath, C., 2008. Patents and the performance of voluntary standard-setting organizations. Management Science 54, 1920-1934.

Sampat, B.N.,Ziedonis, A.A., 2004. Patent citations and the economic value of patents. In: Glanzel, F.M.H., Schmoch, U. (Eds.), Handbook of Quantitative Science and Technology Research. Kluwer, Dordrecht, the Netherlands, pp. 277-299.

Schmidt, S.K., Werle, R., 1998. Coordinating Technology: Studies in the Internationa Standardization of Telecommunications. The MIT Press, Cambridge.

Shapiro, C., 2001. Navigating the patent thicket: Cross licenses, patent pools, and standard setting. In: Jaffe, F.A., Lerner, J., Stern, S. (Eds.), Innovation policy and the economy. National Bureau of Economic Research, Cambridge, MA USA.

Shurmer, M., Lea, G., 1995. Telecommunications standardisation and intellectual property rights: a fundamental dilemma? In: Kahin, T.I.B., Abbate, J. (Eds.), Standards Policy for Information Structure. MIT press, Cambridge, MA, USA

Sidak, J.G., 2009. Patent Holdup and Oligopsonistic Collusion in Standard-Setting Organizations. Journal of Competition Law and Economics 5, 123.

Simcoe, T.S., Graham, S.J.H., Feldman, M.P., 2009. Competing on standards? Entrepreneurship, intellectual property, and platform technologies. Journal of Economics \& Management Strategy 18, 775-816.

Taaffe, J., 2000. 3G patents initiative devised to avoid 'Qualcomm-type' disputes. CommunicationsWeek International, June 19, 2000. 
Tilson, D., Lyytinen, K., 2006. The 3G transition: changes in the US wireless industry. Telecommunications policy 30, 569-586.

Trajtenberg, M., 1990. A Penny for your Quotes: Patent Citations and the Value of Innovations. RAND Journal of Economics 21, 172-187.
Van Zeebroeck, N., 2011. The puzzle of patent value indicators. Economics of Innovation and New Technology 20, 33-62.

Wilkinson, S.L., 1991. They're stealing our diamonds: the standards assault on patents. Revue Canadienne de propriété intellectuelle 8, 193-205. 